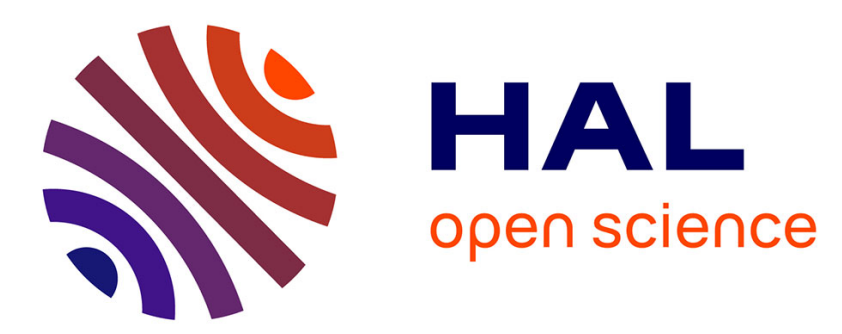

\title{
Strategic decision-making in NPD projects according to risk: Application to satellites design projects
}

François Marmier, Ioana Filipas Deniaud, Didier Gourc

\section{To cite this version:}

François Marmier, Ioana Filipas Deniaud, Didier Gourc. Strategic decision-making in NPD projects according to risk: Application to satellites design projects. Computers in Industry, 2014, 65 (8), pp.1107-1114. 10.1016/j.compind.2014.06.001 . hal-01006418

\section{HAL Id: hal-01006418 https://hal.science/hal-01006418}

Submitted on 16 Jun 2014

HAL is a multi-disciplinary open access archive for the deposit and dissemination of scientific research documents, whether they are published or not. The documents may come from teaching and research institutions in France or abroad, or from public or private research centers.
L'archive ouverte pluridisciplinaire HAL, est destinée au dépôt et à la diffusion de documents scientifiques de niveau recherche, publiés ou non, émanant des établissements d'enseignement et de recherche français ou étrangers, des laboratoires publics ou privés. 


\title{
Strategic decision-making in NPD projects according to risk: application to satellites design projects
}

\author{
François Marmier $^{\mathrm{a}^{*}}$, Ioana Filipas Deniaud ${ }^{\mathrm{b}}$, Didier Gourc $^{\mathrm{a}}$ \\ ${ }^{a}$ Toulouse University, Mines Albi, Centre Génie Industriel 81000 Albi, Cedex 09, France \\ marmier@mines-albi.fr, gourc@mines-albi.fr

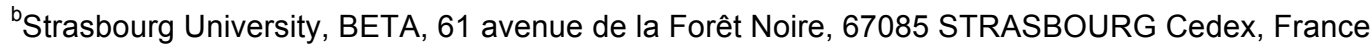 \\ deniaud@unistra.fr
}

* Corresponding author

\begin{abstract}
:
In this paper we present a method for making strategic decisions in New Product Development (NPD) projects based on risks. In NPD the complexity of the process depends both on the nature of the design problem and the difficulties associated with managing the project (activities, risks). To design a complex product several different teams, having different competencies, work on the project. Not one among them controls the entire process. The interactions between product subsystems in NPD often lead to technological arbitration between alternative solutions

In selecting one solution over another, the risk management concerns and the overall project plan are affected. Therefore, the objective is to give the project manager the means to evaluate the effects of strategic decisions, including those that influence the selection of technological solutions for the project plan as well as those for risk treatment strategies.

We propose an integrated process that comprises design, project management and risk management. It takes into consideration the design activities and risk activities to generate a design project planning where design activities and risk activities are folded into the overall design project plan. During the process of project design two different types of strategies are required: one relates to the problem design, the other to the assessment of project risks. Each strategy leads to different possible scenarios. We present a decision tree that shows the decision steps and possible project scenarios. A generic decision support system is proposed. We demonstrate its applicability by applying it to a satellite design project.
\end{abstract}

Keywords:

Design project, Complex product, Project planning, Risk management, Systems engineering

\section{Introduction}

With rapidly changing markets and technologies, today companies developing technological objects face a constant challenge. For these companies, future success often requires that they offer increasingly complex innovative products. Complexity is difficult to manage not only at the product design stage [1], but also in the organization of the project design and in process control.

We have observed that a growing number of highly dynamic companies, in areas as diverse as aeronautical, automotive, and pharmaceutical, find themselves in a constant state of transition. They are frequently required to update their standard products and at the same time must never cease in their attempts to develop new and innovate products. To meet this requirement, the company managers must master the design process both as it applies to exploration and to exploitation [2] If there is an emphasis on exploration, then there will be increased demands on a company's ability to innovate. As design projects require exploration, the more the innovation level is high, the more the number of undesirable events is potentially high. These events also called risk are characterized by probability of occurrence and impacts on the project objectives.

The effects of risk are measured according to the criteria of classic project management especially cost and time. The proposed approach is original since it allows studying the influence of the selection of technologies and the associated risks on the project. To assist the decision maker in selecting one technological solution and the risk treatment strategies, we propose a model integrating the risk management with the design phase. In such situations, this combination strengthens the ability of the "rationally limited" decision maker to identify satisfactory solutions.

In this paper we outline a process for making strategic decisions in New Product Development (NPD) projects according to risk. Our objective is to give the project manager the means to evaluate the effects of decisions including those that influence the selection of technological solutions as well as those for risk treatment strategies. We consider an example of incremental innovation where the project team makes use of its knowledge on different parts/subsystems of the system and the corresponding risks.

First, we characterize different design processes. Then we present different models used to manage design complexity. We show that a Systems Engineering model reduces the complexity in product design. A multi-level system decomposition helps to clarify technical or organizational problems. We provide a flow chart that illustrates the processes leading to arbitration management in a design project. 
We present an overview of the links between activities under the purview of the Project Manager, we propose a model which shows how the processes of design, project management and risk management are unified. We present a methodology and show its applicability in a specific case.

\section{Project risk management in Product Design}

\subsection{Product Design}

In the literature a number of different models have been proposed for exploitation and exploration projects:

Design project models based on exploitation develop a variant of a known product, using predefined specifications and established skills. Design projects are based on pre-specified models: e.g. the single-step waterfall model which does not present the feed-back possibility [3]; Pahl and Beitz model [4] with iterations requiring costly and very long development time $[5,6]$. The project is structured in a number of sequential and linear steps [7]. When one of the process steps becomes blocked, it is necessary to reinitialize the previous step or even to (re)launch the entire process. Organizational structures that develop this type of exploitation project are characterized by detailed and formalized projects and processes; specialized departments focused on the strict division of work.

There are two types of Design models based on exploration:

Systems Engineering was developed by NASA to handle the growing complexity of space systems. In such systems engineering cases, where interdisciplinary collaboration is required, then specific coordination problems and risks can arise. There are two requirements in the need to control exploratory projects: one is the parallelization of tasks, the other is the use of different models (e.g. activity-based model and Vee system model). These models have the advantage of: (1) dividing a system into modules [8] distributed in different layers: from the system level to individual components (Figure 1a) [9]; (2) developing the solution by organizing the project into interrelated subprojects, often represented with the " $V$-cycle" (figure $1 \mathrm{~b})$; (3) transferring the design effort to the oversight level of the design process. This implies that managers and designers become able to guarantee the performance of the design process and to anticipate or prevent major risks of future projects.

\section{[Insert Figure 1 here]}

The nature of the interactions between subsystems often leads to a series of conflicts requiring arbitration. This arbitration process can lead to a redefinition of the initial functions, of the product's initial requirements, or even a redesign of the organization (activity structure) of the project design. A design project implies strategic choices (Figure 2).

\section{[Insert Figure 2 here]}

Either the designers find a way to chose between possible solutions (arbitration) or the managers find solutions to the unresolved contradictions [10,11]. At first, arbitration implies that they must select one solution from a set of known solutions. Arbitration may thus lead to a compromise situation. On the other hand if requirements lead to contradictions that exclude arbitration, two situations can be envisaged:

-the contradiction is insurmountable; this can lead to a redefinition of the design project itself.

-the solution does not exist at the beginning of the design process. Radical innovation overcomes contradictions leading to an extension of the solutions space.

Applying this model means: (1) verification of requirements at different stages of the design process leading to a validated solution; (2) identifying and analyzing in details the contradictions using systems engineering tools; (3) overcoming contradictions as they appear during the design project.

Each design solution implies different risks that must be taken into account in project management.

\subsection{Project risk management}

In the literature, the risk management methodologies refer to a standard process presenting the well-known steps: risk identification, risk evaluation and quantification, risk mitigation for treatment and/or impact minimization and risk monitoring $[12,13]$. Tixier et al. propose a classification of sixty-two existing approaches [14]. They sort methods depending on whether they are deterministic and/or probabilistic, and also whether they are qualitative or quantitative. Within the context of a project, a risk occurrence may introduce: (1) the modification of existing tasks related to the risks influencing on duration or cost. (2) the modification of the project structure by risk treatment strategies. This therefore impacts the project planning: cost and duration. The specificities of the project context are: the notion of uniqueness, the notion of limited horizon (different milestones and contractual commitments), and the notion of a multi-expertise environment (different actors). Several academic research works propose methods to complement the different phases of the global approaches, such as the optimisation of different criteria during the schedule or after the identification phase $[15,16]$. In parallel to these global approaches, several authors propose methodologies to manage the risk in projects. Gourc et al. [17] propose a reading grid of the risk management approaches as follows: the symptomatic approach and the analytic approach. The first group of approaches, called risk-uncertainty, is associated with approaches where project risk management is transformed into project uncertainty management [18] using the Monte Carlo simulation method [19]. The second approach family considers risk as an event that can affect the achievement of the project objectives [20]. Risk is described as an event, which has occurrence characteristics (potentiality to occur) and consequence characteristics on the project objectives (impact in the event of occurrence). The risk level also labelled criticality is then obtained by multiplying the probability of the event and its impact [21]. Project management and risk management processes are generally presented as independent. Each process is described with precision but the interrelations, which may exist, are never shown. The hypothesis of independence between 
risk process and project planning process being overly simplistic, Pingaud and Gourc [22] propose a project management approach based on a synchronised process of project schedule and risk management. Nguyen et al. propose the method ProRisk, supported by a software tool (available online at http://prorisk.mines-albi.fr) that assists in modelling and evaluating the impact of risks on the project cost and the schedule cost [23]. They define the concepts of risk scenario, treatment scenario and project scenario. This approach uses the synchronized processes proposed by Pingaud and Gourc [22].

The project management of new product development (NPD) is well-known for its reference to the innovation. Risks are intrinsic in NPD in all industries [24]. Thus firms need to take initiatives to reduce risks that are related to NPD. The risk management framework should integrate the three most important risk factors that affect NPD performance: technology, marketing, and organization [25]. In NPD management, decision-makers have to choose exclusively one orientation as strategy development according to a global risk level tolerance. As an answer, decision trees (DT) are regularly used in the literature on decision [26]. DT is a structure that represents decision problems with exclusive and competing solutions. It makes it possible to find optimal solutions to short-time dynamic decision problems [27]. Based on decision variables, decision tree allows managers to choose one way and to react within this way in front of events. To increase the efficiency of innovation, the link between the selection of innovative technological solution and the modification the project structures has to be made.

\section{Proposed development}

In this work, we focus on the decision making process in design project management and risk management by analysing the consequences of the risk "as an event" in the exploratory design project.

Literature review about design project gives us a focus on the means to decompose projects in macro activities that are classically used to plan. A process synchronizing the project schedule and risk management allows for the planning and integrating of the risks and their treatments [22]. The use of DT permits us to formalize the successive decisions made by a decision maker.

Little account is taken of the risks and the strategies to deal with the selection of the technological solutions and their repercussions on the design project. Moreover, there is no tools helping the project manager evaluate the solution of the project design problem and its consequences on (1) the risks and their associated treatment strategies, (2) the planning of a design project.

By taking into account the fact that well-managed risks related to the technological solution lead to better NPD performance [28], our objective is to propose a complete framework helping decision-makers to decide innovation and risk treatment strategies. Our approach should facilitate the decision-making processes by creating links between project management, risk management and design management and by showing the consequences of technological solutions on the planning and on the risk (the risk itself and its treatment). This process allows us to view the consequences of the decisions: when a technological solution is selected, what happens to the associated risks and what effect do these changes have on risk treatment strategies and the project schedule?; When a risk prevention strategy is decided, what would be the consequences for the technological solution and for the project schedule?; and when a plan is created, what are the consequences for the technological solution and for the risk management?

The various possible scenarios and their evaluations will be presented to the project manager. A decision process will make it easier to find the appropriate technological solution and the needed risk treatments.

\subsection{Assumptions}

The proposed model is based on three main assumptions.

- Integration of risk into the project management can affect the duration and the cost criteria for the project. The considered impacts (modification or suppression of an existing task or insertion of a new task for example) influence the project duration and cost.

-The resource aspects, such as the available skills, are not considered for the moment in the model.

-When the decisions for treatment strategy and technological solution need to be made, the tasks list and the risks list are known. The risks and their characteristics are identified and listed since an approach such as the Delphi method has been previously applied [29]. This method helps risk managers characterize the risk dimensions (the impacts and probabilities are rather subjective). It uses different anonymous questionnaires for eliciting experts' opinion to reach a consensus. The risk assessment step can require gathering a significant amount of data. Data gathering may require considerable time. This work does not attempt to develop any tools to improve the data collection method.

At any time, the objectives of the model are (1) to analyse the possible scenarios, (2) to evaluate the global risk level, i.e. the global risk level represents the chance for the project to satisfy commitments, (3) to select the best treatment strategies.

\subsection{Formalization of the decision process in design project}

At the first step of the Vee-cycle, the need for the proposed product is analyzed. Different technical solutions provide possible answers to the same functional need. The first decision at the end of the need analysis is to select the solution that will be developed during the design project. In Figure 3, we represent this decision by the square D1. Typically, several options are possible. In the Figure 3, three technical solutions (A to $\mathrm{C}$ ) are possible.

$$
\text { [Insert Figure } 3 \text { here] }
$$

For each one of these solutions, it is possible to draw up a plan using the Project Planning Process (noted PPP in Figure 3). This is part of the synchronized process described in [22]. Based on the selected plan the Project Manager (PM) has to 
organize the treatment of the risks over the design project. In that way, the decision, noted D2 ${ }^{(\mathrm{A} \text { to } \mathrm{C})}$ in the Figure 3 , consists in choosing the preventive risk treatment strategy in the project for the chosen technical solution. The Risk Management Process (RMP in Figure 3) is performed to identify the risk treatment and the PPP is developed a second time to plan the risk treatment tasks as well as to integrate others modifications to the plan. These two decisions are made in the preparation phase of the project.

The PM has also to plan the possible project development. In that way the chance node $\mathrm{E}$ characterizes the possible occurrence of risks. For each possible set of occurrences, D3 ${ }^{(A)}$ to $)$ represents the decision of corrective strategies that could be carried out during the whole design project (from the requirement specification phase to the validation phase). D3 is planned during the preparation phase in order to meet the occurrence of risk during the project running phase. D3 is supposed to reprocess the RMP and the PPP as well as to integrate new information and to obtain the final planning.

The decision tree, in Figure 4, gives a complementary view of the succession of decisions. The example concerns the choice of the technical solution A in D1. The PPP is then developed. The second decision $\left(D 2^{A}\right)$ selects the risk treatment strategy. For all the decisions, the RMP has to be developed followed by a second cycle of the PPP (PPP' in Fig 3). Then, for all the possible sets of risk occurrence, the last decision $\left(D 3^{A}\right)$ concerns the corrective risk treatment strategy. $D 3^{A}$ gives a planned and global vision of all the possible corrective risk treatments that will be carried out for the duration of the design project. A second cycle of the RMP and a third cycle of the PPP are required (RMP' \& PPP" in Fig 4).

\section{[Insert Figure 4 here]}

\subsection{Objectives}

When different possible projects are studied to satisfy the same need, the repercussions on the risks are rarely anticipated in the classical approach. The project manager has to consider the profitability of each technological solution, but also the consequences with regard to the risk level. A technological solution that incorporates the required functional needs must be selected. The selection is a multicriteria problem. When the project manager makes the decision, the number of criteria used to evaluate the proposal is often reduced to the main ones: the cost, which is a sensitive and finite resource, and the duration, which traditionally is a matter of contractual commitment. These criteria are not totally independent. In this study, to be able to handle the potential contractual cost overruns and delays, as well as the probability that different events occur, choices must be made in order to characterize project scenarios. The decisions then are based on an analysis on the analysis of criticality.

\subsection{Data}

$P^{t s}(t s=0, \ldots, T S)$ is a Project associated to a particular technological solution ts, TS being the number of possible technological solutions and then potential projects.

Each $P^{t s}$ is described by its tasks $T_{t}^{t s}\left(t=1 \ldots T^{t s}\right), T^{t s}$ being the number of project tasks of $P^{t s}$. The planning process gives an initial planning $P i^{t s}$ that does not integrate any risks. A project is also described by its set $E_{R}{ }^{t s}$ of identified risks $R_{i}^{t s}\left(i=1 \ldots n^{t s}\right)$, $n^{t s}$ being the number of identified risks in $P^{t s}$. Each $R_{i}^{t s}$ is characterised via the risks management process. A risk $R_{i}^{t s}$ is also characterized by its period of occurrence, i.e. the tasks during which the risk can occur. It has a probability proba( $\left.R_{i}^{t s}\right)($ the probability that the event related to $R_{i}^{t s}$ occurs) and impacts in costs $C l\left(R_{i}^{t s}\right)$ and/or in duration $D I\left(R_{i}^{t s}\right)$ on a task. This task can be different from the period of occurrence. These probability and impact are also called initial probability and initial impact. The initial impact allows consideration of the fact that the task is running in a graceful degradation.

A risk scenario $S c R_{s}^{t s}$ corresponds to a combination of the risks that are considered as occurring during a project $P^{t s}$. A project presenting $n$ risks leads to $2^{n}$ risks scenarios. Then $S_{c} R_{s}^{t s}\left(s=1, \ldots, 2^{n}\right)$ is a possible achievement with $k$ risks $(0 \leq k \leq n)$ and the total number of risk scenarios, presenting $k$ of the $n$ identified risks, is equal to $n ! / k(n-k) !$. It has a probability proba $\left(S c R_{s}^{t s}\right)$ (the probability that the events related to this risk scenario occur and that the other risks do not occur).

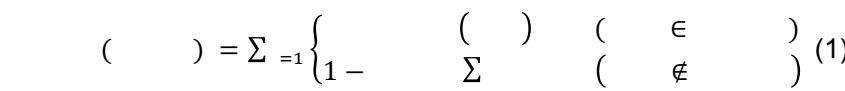

Each risk can be treated in various ways that can be preventive, corrective or a combination of several actions. A risk $R_{i}^{t s}$ can be associated to one or more treatment strategies $S t T_{i j}^{t s}\left(j=1 \ldots m^{t s}\right), m^{t s}$ being the number of identified strategies for $R_{i}^{t s} . A$ treatment strategy $S t T_{i j}^{t s}$ groups a set of treatment actions $A_{i j \alpha}(\alpha=1 \ldots a)$ to avoid or reduce the risk $R_{i}^{t s}$, a being the number of identified treatment actions. A treatment action can be materialized by a task to achieve and it can introduce three types of modification to the WBS: (a) addition of a new task, which generates a new action to be implemented; (b) suppression of a task from the initial schedule. The risk is reduced by suppressing a task from the schedule; (c) modification of an existing task.

A treatment strategy is a preventive strategy if it contains at least a preventive treatment action. Otherwise, it is a corrective strategy. If the strategy consists in running no action at all, it is noted as being an empty set such as $\varnothing$ (i.e. graceful degradation).

The treatment actions can be common to several risk treatment strategies. The set of all the identified $S t T_{i j}^{t s}$ for a risk $R_{i}^{t s}$ is written $S t R_{i}^{t s}$.

Then $S t R_{i}^{t s}=\left(\varnothing, S t T_{i 1}^{t s}, \ldots, S t T_{i j}^{t s}, \ldots, S t T_{i m}^{t s}\right)$ and $\operatorname{Card}\left(S t R_{i}^{t s}\right)=m^{t s}+1$

A treatment scenario $S_{c} T_{d}{ }^{t s}\left(d=1 \ldots D^{t s}\right)$ corresponds to a combination of the treatment strategies chosen to deal with the different risks of $P^{t s}$. The set of treatment scenarios is given by: $\mathrm{E}_{\mathrm{ScT}}=\sum_{\mathrm{i}=1}^{\mathrm{n}} \mathrm{StR}_{\mathrm{i}}$. For each $P^{t s}$, $E_{S c T} t_{s}$ may contain a set of preventive treatment scenarios $E_{S c T p r e v}{ }^{t s}$ and corrective treatment scenarios $E_{S c T c o r r e c}{ }^{t s}$.

The proba $\left(R_{i}^{t s} \mid S t T_{i j}^{t s}\right)$ is the probability that the event related to $\mathrm{R}_{\mathrm{i}}^{t s}$ occurs knowing that $S t T_{i j}^{t s}$ (preventive strategy) has been done. This probability, as well as the impacts $C I\left(R_{i}^{t s} \mid S t T_{i j}^{t s}\right)$ and $D I\left(R_{i}^{t s} \mid S t T_{i j}^{t s}\right)$, are then qualified as "reduced". 
A project scenario $S c P_{p}^{t s}(p=1 \ldots P)$ is defined as being a possible project achievement that is built with a risk scenario and treatment scenario $\left(S c P_{p}^{t s}=<P i^{t s}, S c R_{s}{ }^{t s}, S c T_{d}^{t s}>\right)$. The set of project scenarios $E S^{t s}$ is obtained by combining the set of risk scenario and the set of treatment scenario.

proba $\left(S c P_{p}{ }^{t s}\right)$ is the probability of a given $S c P_{p}{ }^{t s}$. It takes into account (2) the probability of the occurring risks $\left(R_{i}^{t s} \in S c R_{s}^{t s}\right)$, (3) the probability that several risks does not occur $\left(R_{i}^{t s} \notin S c R_{s}^{t s}\right),(4)$ the probability of the occurring risks $\left(R_{i}^{t s} \in S c R_{s}^{t s}\right)$ knowing that a treatment strategy is developed $\left(S t T_{i j}^{t s} \in S c T_{d}^{t s}\right)$ (5) the probability that $R_{i}^{t s}$ does not occur $\left(R_{i}^{t s} \notin S c R_{s}^{t s}\right)$ knowing that a preventive strategy has been processed and the initial probability has been modified $\left(S t T_{i j}^{t s} \in S c T_{d}^{t s}\right)$.

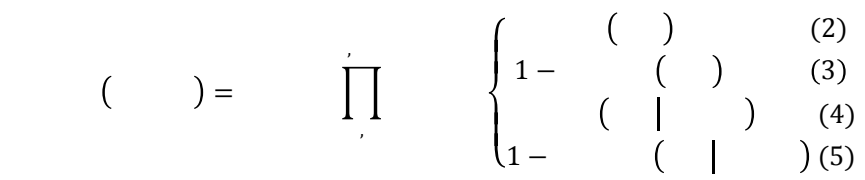

The cost of a project scenario is noticed $C\left(S c P_{p}{ }^{t s}\right)$. It includes the cost of the $T^{t s}$ tasks that constitute the initial planning of the project, the $S c R_{s}^{t s}$ and the chosen $S c T_{p}^{t s}$ and (6) The Global Cost $G C^{\text {initial }}\left(R_{i}^{t s}\right)$ of the occurring risks that are not treated by the treatment strategies. It includes the cost impact that is composed by a fixed part of the total cost (materials, tools, parts, etc.) and by an indirect cost that depends on the action duration, through the Delay Impact, and the actors charge. (7) The reduced global cost impact $G C^{\text {reduced }}\left(R_{i}^{t s}\right)$ that is obtained taking into account the different strategies $S t T_{i j}^{t s}$ applied to treat $R_{i}^{t s}$ and its reduced repercussions on the project cost and duration. (8) The cost of the treatment strategies $S t T_{i j}^{t s}$ that is determined by the cost of the action is composed by a direct cost (materials, tools, etc.) and by an indirect cost that depends on the action duration and on the actors.

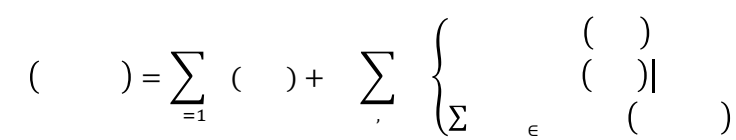

Each $S c P_{p}{ }^{t s}$ can be characterized by a criticality $\operatorname{Cr}\left(S_{c} P_{p}{ }^{t s}\right)$. This criticality measure is based on its probability of occurrence proba $\left(S c P_{p}^{t s}\right)$ and its impact $\left(S c P_{p}^{t s}\right)$. impact $\left(S c P_{p}^{t s}\right)$ is calculated based on a duration and a cost metrics of the project scenario respectively $a_{p}^{t s}$ and $\beta_{p}^{t s}$ :

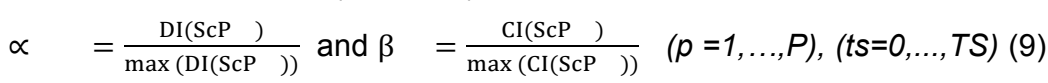

then $\alpha_{p}{ }^{t s}, \beta_{p}{ }^{t s} \in[0,1]$.

Where $\mathrm{Cl}\left(\mathrm{ScP}_{p}{ }^{t s}\right)$ and $\mathrm{DI}\left(\mathrm{Sc}_{c} P_{p}{ }^{t s}\right)$ are respectively the distance between the Cost and Duration Impacts and the budget and duration thresholds defined in the contractual agreement of the project. $\max \left(\mathrm{Cl}\left(\mathrm{ScP}{ }_{p}^{t s}\right)\right)$ and $\max \left(\mathrm{Cl}\left(\mathrm{ScP} \mathrm{P}_{p}^{t s}\right)\right)$ the distance of the costly and longest project scenario possible over the whole design project.

The global impact, weighted and normalised, $\operatorname{Impact}\left(S c P_{p}{ }^{t s}\right)$ is then obtained through the following formula:

$\operatorname{Impact}\left(S c P_{p}^{t s}\right)=\mathrm{q} \times \alpha_{p}^{t s}+\mathrm{q}^{\prime} \times \beta_{p}^{t s}$

Where $q$ and $q^{\prime}$ (respecting $q+q^{\prime}=1$ ) are two coefficients that are chosen by the project manager in accordance with the importance of the duration relatively to the cost.

Then, $\forall p, \forall$ ? 圆, $\operatorname{Cr}\left(\operatorname{Sc} P_{p}^{t s}\right)=\operatorname{proba}\left(\operatorname{Sc} P_{p}^{t s}\right) \times \operatorname{impact}\left(S c P_{p}^{t s}\right)$

\section{Resolution approach}

In the preparation phase of a project, the technical orientations and the way of managing risks need to be selected. This has to be done both for the planning and for the ability to respond to events as they occur during the running phase. The approach we propose uses data relative to the project in its classical view: the different tasks are planned, the risks identified, and the associated treatments prepared. This approach also uses data relative to technical solutions and their modifications: namely consequences for the tasks and consequently for the risks and treatment strategies. The data should be collected on the basis of expert knowledge concerned by the project. Therefore, our method includes input data provided by the schedule process (management team) and from the risk management process;

The main approach has two phases: (1) the construction of the Decision Tree (DT), from the first decision node to the leaves, (2) the resolution of the DT by working backward method.

\subsection{The construction of the DT}

The generation of the DT consists in building the set of possible project scenarios in light of the identified risks and risk treatment actions and their evaluations for each technological solution studied. The project scenarios are the leaves of the tree. To evaluate the different possible project scenarios, the management team needs to generate an initial schedule for each technical solution, without integrating the notions of risk and risk treatment. Depending on the difference between the technical solutions, the outcomes can be rather similar or rather different.

It is then necessary to calculate the different risks and treatment scenarios. These scenarios allow the set of the project scenarios to be constructed. Finally, when the project scenarios are known it is possible to determine the times and costs in each case. This approach based on ProRisk, proposed in $[23,30]$, is then used to generate $E S^{t s}$. The probability calculation method for each project scenario differs, depending on whether the project scenarios contain a treatment strategy or not. For each project scenario, the calculation the probability, the cost and the duration take into account potential modifications induced by the achievement of treatment strategies at the schedule level. Once the initial schedules have been adapted in accordance with the studied scenario (modified duration, tasks added or removed), the project scenario duration is computed using the PERT method and the earliest starting dates. 


\subsection{The resolution of the DT}

The backward method's resolution consists in studying the effects of the different decisions from the leaves to the root of the tree (i.e. from D3 to D1 in Fig 4). Through the use of this knowledge it is possible to become proactive. Therefore, the number of steps of this phase depends on the number of decisions in the DT: 3 for the problem under consideration.

Step (1) consists in finding for each branch of the DT, the best D3. In each branch, D1 and D2 are known and the best D3 can be determined. D3 $s$ the decision that selects the corrective strategies associated with each $S c R_{s}{ }^{t s}$. They are selected in order to avoid scenarios that would not be possible in the reality, i.g. the scenario where the project is stopped waiting for a corrective action, the scenario presenting a NoGo situation, or the scenario that would be far from acceptable. D3 is made by choosing the corrective strategies that minimize $\mathrm{Cr}\left(\mathrm{Sc} \mathrm{P}_{p}^{t s}\right)$ for all the leaves of the tree.

Step (2) D2 is the second step that composes the selection phase. D2 determines the preventive treatment strategy that is the most adequate for each technical solution. It is made for each studied design project knowing the best D3 made for all the branches. D2 helps to avoid the worst possible cases (project scenarios) as defined by the Savage's criterion often used in decision-making theory [31]. Minimizing the maximum criticality (also called in a similar context regret) can, when the assessment of each scenario is known, measure the regret that the decision-maker would have if he had preferred one action over another. D2 is made by choosing the preventive strategies that minimize $C r_{\max }\left(S c P_{p}^{t s} \mid S c T_{\text {prev }}^{t s}\right), \forall t s$ knowing the selections realized in D3.

Step (3) D1 is the selection of the best technical solution based on its design project. The project management team wants to maximize the chance of meeting the commitments. D1 consists in selecting the technical solution that maximizes the number of possible $\mathrm{ScP}_{p}{ }^{t s}$ respecting the contracted duration and cost.

\section{Application in the satellite industry}

Initially, the different data sets have been characterized by experts referring to their experiences but were slightly modified for confidentiality. The project scenarios go from the needs analysis to the time when the satellite reaches its final orbit.

\subsection{Presentation of the satellite design project}

The application case, developed here to illustrate this research work, considered the development of a small satellite for a scientific mission, based on a different platform. The platform would carry out a predetermined useful load of scientific / technological instruments. Two technological solutions can potentially been used to develop the platform: (A) a classical one using ergol liquid for its propulsion to reach its final orbit following its launch. (B) an innovative solution, completely electrical with a motor using xenon gas ionised and accelerated with the electrical energy provided by two photovoltaic panels.

The second solution allows for a reduced load as the ergols and their associated structures are eliminated: the final weight of the satellite is reduced nearly by half. This then allows for lighter satellites with the same carrying capacity. Therefore, the cost of the launch can be divided by up to two since two satellites can be launched with the same booster rocket. The inconvenience of this low power solution is that six months are required for the satellite to reach its final orbit.

The selected solution would go through the different phases of the Vee-cycle. Table 1 presents the phases of the projects for both solutions.

\section{[Insert Table 1 here]}

The phase durations are presented in Time Units (TU) with a fixed rate and their costs in Monetary Units (MU). Conflicting requirements complicate the project. For example, the need for high onboard power $(>100 \mathrm{~W})$, a low satellite mass $(<120 \mathrm{~kg})$, a low volume $(<1 \mathrm{~m} 3)$, a long life time $(>2$ years $) \ldots$

There are risks associated with either of the two cases as contractual commitments of 37 TU and 44 MU for this part of the global satellite project have been established. Different risks were identified during the project. A shortlist has been selected for the application case and is presented in Table 2. This list permits to respect the confidentiality of the industrial data and the relevance of the risks for the sake of the demonstration.

\section{[Insert Table 2 here]}

Their associated cost is a fixed cost that is added to the one based on the new task duration. Possible treatment strategies characterize them (Table 3). The impacts of one risk are judged as infinite since the costs and delays will continually increase until an action is decided. NC (Not Changed) means that the strategy does not modify the impact of the risk. As an example, the risk $R_{4}$, expresses the anomaly observed during the material integration on the satellite (error of wiring, systems presenting default...). If such a risk occurs, the production is immediately stopped until a strategy is implemented. Then two strategies are possible in both versions of the project: a preventive one and a corrective one. $\mathrm{StT}_{41}{ }^{\mathrm{A}}$ and $\mathrm{StT}_{41}{ }^{\mathrm{B}}$, consist in carefully checking the actual components constructed by the subcontractor as both the manufacturer and the subcontractor carry out the reviews, auditing etc. If it did not completely eliminate the risks, it reduced their probability of occurrence by $10 \%$. The cost of these actions is estimated at $2 \mathrm{MU}$ for planned modifications that are not located on the critical path. StT ${ }_{42}{ }^{\mathrm{A}}$ and $\mathrm{StT}_{42}{ }^{\mathrm{B}}$ aim to modify the material or the software when problems are observed. Such a strategy costs $1 \mathrm{MU}$ and makes the satellite unavailable for $1 \mathrm{TU}$. If $\left(R_{4}\right)$ occurs even if a preventive strategy has been carried out, it is still possible to develop the corrective strategy. However, only its duration will be taken into account, since the cost will be supported by the suppliers. 
[Insert Table 3 here]

\subsection{Results and discussion}

Table 4 presents the results obtained with this approach. The first column shows the different technical solutions. The second column gives the possible preventive strategies. $\varnothing$ means that the preventive strategy consists in undertaking no action. The third column presents the number of project scenarios containing the previously mentioned preventive strategies. The column entitled "\% Pertinents" refers to the percentage of pertinent project scenarios. Those scenarios, labelled non-pertinent, in which one or more risks occurred are inapplicable. These projects are stopped without any corrective strategies despite the presence of possible preventive strategies. Then a corrective strategy should have be applied. The next column presents the maximal criticality among the pertinent scenarios. Still, among the pertinent scenarios, the last column shows the percentage of scenarios that respect the contractual commitments. The variant that maximizes the number of project scenarios in the agreement zone is presented in bold in the last column of Table 4 . This result means that by choosing the solution A and by applying no preventive treatment strategy, $66 \%$ of the pertinent project scenario respects the contractual commitments. Based on these results, the recommendation to the project manager would be simple: choose solution $A$ and apply no preventive strategy.

Concerning the method, the universe of the events that may happen during a project is important. Their characterization and the characterization of their effects necessitate having and manipulating a large quantity of information. It is one of the elements that confer to our model a proximity to reality. Therefore, it is necessary to have and to be able to manipulate this information if we want to explore the set of the possible futures for large project, in order to assist the decision maker. Then, the need to characterize possible futures for the project leads necessarily to build a model rich in information.

The results of the application case have been presented and discussed with industrial partners. The approach presenting successive steps of planning and risk integration is representative of their reality. These decisions proposed following the approach were consistent with their perceptions of what were the best decisions in the studied context. The application case is simplified for the sake of the demonstration. The approach is flexible since it can be used in a different context.

[Insert Table 4 here]

\section{Conclusions and Perspectives}

In NPD the interaction between the subsystems of the product often leads to conflicts requiring arbitration between alternative solutions. To choose the best technical solution and to determine the optimal risk treatment strategy in the preparation phase of a project is often quite complex, especially when the project should deliver a product presenting technological innovation. If the benefit of such a solution is easy to evaluate qualitatively, then each possible solution potentially developed through the design project generates different planning needs, different costs, durations as well as different risk levels. To estimate the risk level for each project variant, we propose an approach to model and evaluate the impact of risks on the project cost and the schedule cost. This approach uses the synchronized process principle and takes into consideration the repercussion of the project structure modifications on risks and the global risk level. We use the concepts of risk scenario, treatment scenario and project scenario to characterize and evaluate the project solutions. We illustrate the principles of our approach through an application case from the aerospace industry. This methodology analyses the possible scenarios, evaluates the global risk level and selects the best treatment scenarios at any time. An estimate of the global risk level of each solution can be made and gives a vision of the possible scenarios: from the least to the most probable, from the most disastrous to the most optimistic. We have developed a software tool that illustrates this process. As the occurrence of a risk can modify the project, in this new context, the remaining risks can change and new risks can occur. Most of the different project risk analysis methods study risks under the hypothesis of independence between risks. However, interdependencies exist between risks and can influence risk evaluation. Few research works treat model risk interdependency [32]. The main perspective for this research work is to examine the influence of previously occurring risks as initialized through the model proposed in $[33,34]$. The integration of human resource constraints into the model, as well as the limiting availability of resources that can be shared over several projects represent a variety of interesting perspectives.

\section{Acknowledgment}

The authors would like to address special thanks to Mr Denis Donnelly for his contribution to the improvement of the paper quality.

\section{References}

[1] M. Hobday, Product complexity, innovation and industrial organisation, Research Policy 26 (1998) 689-710.

[2] J. March, Exploration and exploitation in organizational learning, Organization Science 2(1) (1991) 71-87.

[3] W. Royce, Managing the Development of Large Software Systems: Concepts and Techniques, Proceedings of IEEE WESCON 26 (1970) 1-9.

[4] G. Pahl, W. Beitz, J. Feldhusen, K.H. Grote, Engineering Design, A Systematic Approach, 3rd Edition (2007) Springer.

[5] G. Anand, R. Kodali, Development of a conceptual framework for lean new product development process, International Journal of Product Development 6(2) (2008) 190-224.

[6] S. Biazzo, Flexibility, structuration, and simultaneity in new product development, The Journal of Product Innovation Management 26(3) (2009) 336-353. 
[7] R. Sanchez, J. Mahoney, Modularity, Flexibility, and Knowledge Management in Product and Organization Design, Strategic Management Journal 17 (1996) 63-76.

[8] K.T. Ulrich, S.D. Eppinger, Product Design and Development, New York, McGraw-Hill, 2000.

[9] K.Forsberg, H. Mooz, The Relationship of System Engineering to the Project Cycle, INCOSE (1991) 57-65.

[10] C. Belleval, I. Deniaud, C. Lerch, A model for the management of design project issues: The case of the microsatellites design, International Journal of Design and Innovation Research, 5(1) (2010).

[11] R. Houssin, A. Coulibaly, An approach to solve contradiction problems for the safety integration in innovative design process. Computers in Industry (62) (2011) 398-406.

[12] BSI, 2000. BS 6079-3: Project management - guide to the management of business related project related.

[13] ISO 31000, 2009. International Standards for Business, Risk management - Principles and guidelines.

[14] J. Tixier, , G. Dusserre, , O. Salvi, D. Gaston, Review of 62 risk analysis methodologies of industrial plants, Journal of Loss Prevention in the Process Industries 15(4) (2002) 291-303.

[15] M. Kiliç, G. Ulusoy, F. S. Serifoglu, A bi-objective genetic algorithm approach to risk mitigation in project scheduling, International Journal of Production Economics 112(1) (2008) 202-216.

[16] S. Van de Vonder, E. Demeulemeester, W. Herroelen, and R. Leus, The use of buffers in project management: The trade-off between stability and makespan, International Journal of Production Economics 97(2) (2005) 227-240.

[17] D. Gourc, Towards a general risk model for piloting goods and service related activities. HDR, INP Toulouse, France, 2006.

[18] S. Ward, C. Chapman, Transforming project risk management into project uncertainty management, International Journal of Project Management 21(2) (2003) 97-105.

[19] M. H. Kalos, P. A. Whitlock, Monte carlo methods, Wiley-VCH, 2008.

[20] B.Carter, T. Hancock, J. Morin, N. Robin, Introducing RISKMAN: the European project risk management methodology, The Stationery Office, 1996.

[21] BS 5760-5. Guide to failure modes, effects and criticality analysis (FMEA and FMECA).

[22] H. Pingaud, D. Gourc, Approach of controlling an industrial project by the risk analysis, 5e Congrès de Génie Industriel, Canada (2003)

[23] T. Nguyen, F. Marmier, D. Gourc, A decision-making tool to maximize chances of meeting project commitments, International Journal of Production Economics 142(2) (2013) 214-224.

[24] Y. H. Kwak, K. S. LaPlace, Examining risk tolerance in project-driven organization, Technovation 25(6) (2005) 691-695.

[25] D. S. Doering, R. Parayre, Identification and assessment of emerging technologies, Wharton on Emerging Technologies, john wiley \&sons edn, New York, 2000.

[26] Y. Chiu, B. Chen, J. Z. Shyu, G. Tzeng, An evaluation model of new product launch strategy, Technovation 26(11) (2006) 1244-1252.

[27] R. T. Clemen, Making Hard Decisions: An Introduction to Decision Analysis, 2 ${ }^{\text {edn }}$, Duxbury, 1997.

[28] J. Mu, G. Peng, D. L. MacLachlan, Effect of risk management strategy on NPD performance, Technovation 29(3) (2009) 170-180.

[29] N. Dalkey, O. Helmer, An experimental application of the DELPHI method to the use of experts, Management Science $9(3)(1963)$ 458- 467.

[30] F. Marmier, D. Gourc, F. Laarz, A risk oriented model to assess strategic decisions in new product development projects, Decision Support Systems 56 (2013), 74-82.

[31] J. Petar, Application of sensitivity analysis in investment project evaluation under uncertainty and risk, International Journal of Project Management 17(4) (1999) 217-222.

[32] F. Marle, L.A. Vidal, J.C. Bocquet, Interactions-based risk clustering methodologies and algorithms for complex project management, International Journal of Production Economics 142 (2013) 225-234.

[33] T.H. Nguyen, D. Gourc, Towards a model for assessing risk impact on project planning, in: 22nd International Project Management Association (IPMA) World Congress (2008).

[34] T.H. Nguyen, Contribution to the planning project: model for evaluating scenarios of risk project. In french (Contribution à la planification de projet : proposition d'un modèle d'évaluation des scénarios de risque-projet), PhD thesis (2011). 


\section{Figures}

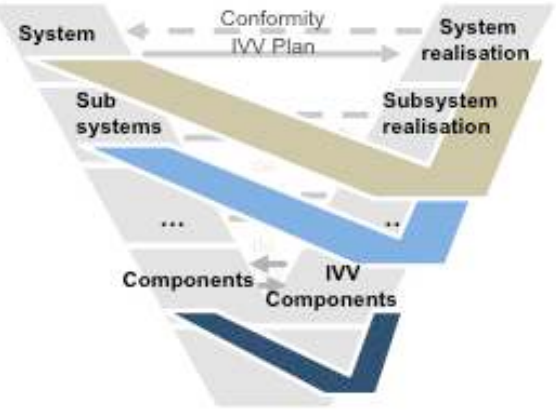

a)

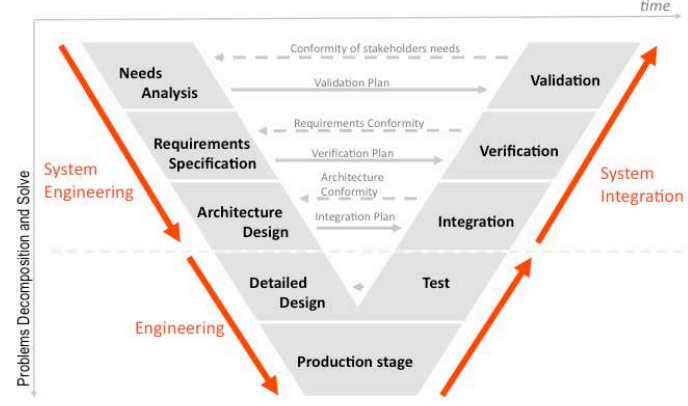

b)

Figure 1: Vee cycle.

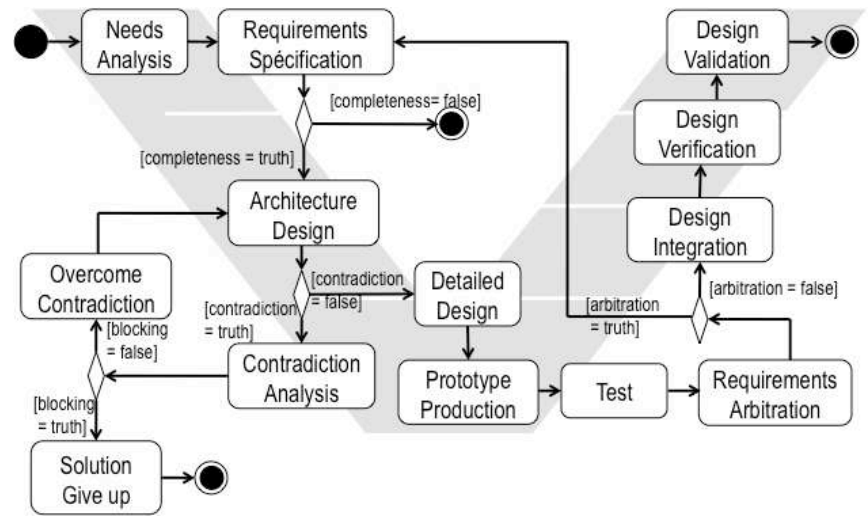

Figure 2: Exploratory design activity based model. 


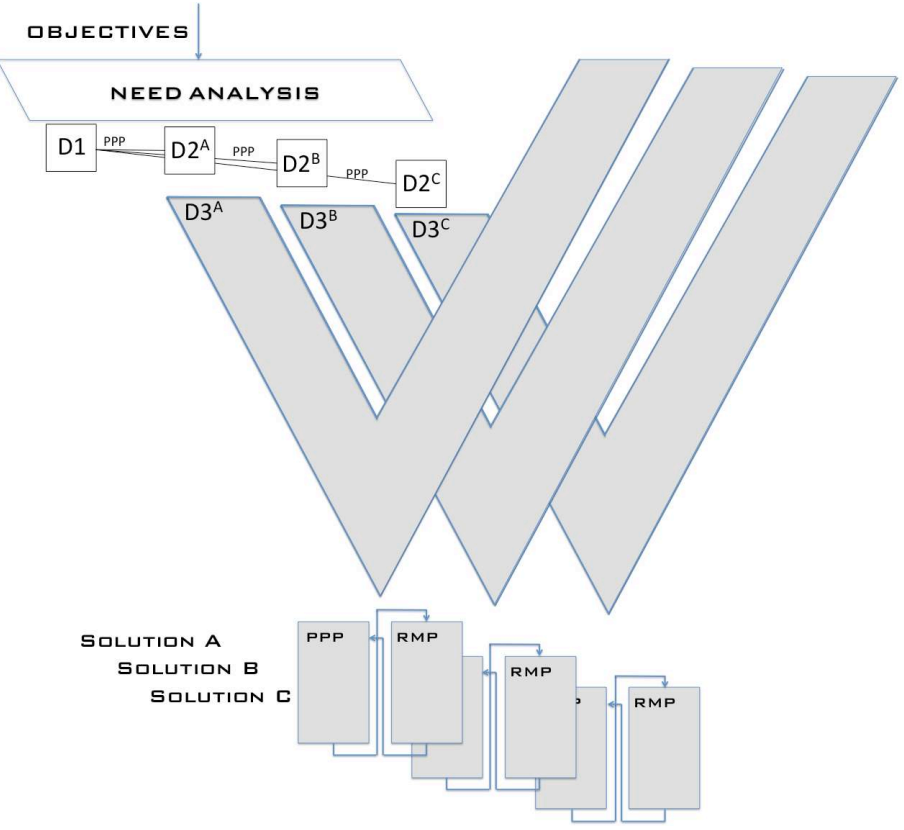

Figure 3: Link between the $\mathrm{V}$ cycle, the decision tree and the synchronized process.

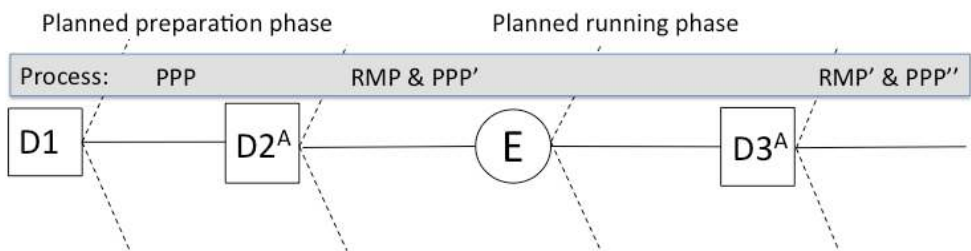

Figure 4: Decision tree in design project $\mathrm{A}$. 
Table 1: Phases of the two projects

\begin{tabular}{|c|l|r|r|r|r|}
\hline \multirow{2}{*}{ General design tasks } & \multicolumn{2}{|c|}{ Solution A } & \multicolumn{2}{c|}{ Solution B } \\
\cline { 2 - 6 } & Time & Cost & Time & Cost \\
\hline T1 & Need analysis & 2 & 2 & 2 & 2 \\
\hline T2 & $\begin{array}{l}\text { Requirement } \\
\text { specification }\end{array}$ & 3 & 2 & 3 & 2 \\
\hline T3 & $\begin{array}{l}\text { Functional } \\
\text { architecture } \\
\text { design }\end{array}$ & 2 & 3 & 2 & 3 \\
\hline T4 & $\begin{array}{l}\text { Physical } \\
\text { architecture } \\
\text { design }\end{array}$ & 2 & 2 & 2 & 2 \\
\hline T5 & Detailed design & 3 & 3 & 4 & 4 \\
\hline T6 & Production stage & 4 & 4 & 4 & 4 \\
\hline T7 & Test & 3 & 5 & 3 & 5 \\
\hline T8 & Integration & 2 & 4 & 3 & 4 \\
\hline T9 & Verification & 2 & 3 & 2 & 3 \\
\hline T10 & Validation & 1 & 1 & 1 & 1 \\
\hline T11 & Flight & 2 & 8 & 4 & 4 \\
\hline Total & 26 & 37 & 30 & 34 \\
\hline
\end{tabular}

Table 2: Risks in the 2 versions of the project

\begin{tabular}{|c|c|c|c|c|c|}
\hline \multirow[t]{2}{*}{ Risk } & \multirow{2}{*}{$\begin{array}{l}\text { Version of } \\
\text { the project }\end{array}$} & \multirow{2}{*}{$\begin{array}{l}\text { Occurrence } \\
\text { probability }\end{array}$} & \multirow{2}{*}{$\begin{array}{l}\text { Occurrence } \\
\text { period }\end{array}$} & Impact & \multirow{2}{*}{$\begin{array}{c}\text { Strategies } \\
\text { (c: corrective, } \\
\text { p: preventive) }\end{array}$} \\
\hline & & & & TU/MU & \\
\hline \multirow[t]{2}{*}{$\mathrm{R}_{1}$ Non accepted component } & A & 0.1 & \multirow{2}{*}{ T5 } & $\mathrm{T} 5+2 / 2$ & $\mathrm{StT}_{11}{ }^{\mathrm{A}}(\mathrm{c})$ \\
\hline & B & 0.8 & & $\mathrm{~T} 5+3 / 2$ & $\mathrm{StT}_{11}{ }^{\mathrm{B}}(\mathrm{p}), \mathrm{StT}_{12}{ }_{(\mathrm{c})}^{\mathrm{B}}$ \\
\hline \multirow[t]{2}{*}{$\mathrm{R}_{2}$ Difficulties of communication } & $A$ & 0.05 & \multirow{2}{*}{ T5 } & $\mathrm{T} 5+4 / 4$ & $\mathrm{StT}_{21}{ }^{\mathrm{A}}(\mathrm{p}), \mathrm{StT}_{21}{ }^{\mathrm{A}}(\mathrm{c})$ \\
\hline & B & 0.3 & & $\mathrm{~T} 5+4 / 4$ & $\mathrm{StT}_{21}{ }^{\mathrm{B}}(\mathrm{p}), \mathrm{StT}_{22}{ }^{\mathrm{B}}{ }_{(\mathrm{c})}$ \\
\hline $\mathrm{R}_{3}$ Lateness of material reception & B & 0.2 & T6 & $\mathrm{T} 6+2 / 10$ & $\mathrm{StT}_{31}{ }^{\mathrm{A}}(\mathrm{p})$ \\
\hline \multirow{2}{*}{$\begin{array}{l}\mathrm{R}_{4} \text { Failure of a component or } \\
\text { software }\end{array}$} & A & 0.25 & \multirow{2}{*}{ T7 } & $\infty / \infty$ & $\mathrm{StT}_{41}{ }^{\mathrm{A}}(\mathrm{p}), \mathrm{StT}_{42}{ }^{\mathrm{A}}(\mathrm{c})$ \\
\hline & B & 0.35 & & $\infty / \infty$ & $\mathrm{StT}_{41}{ }^{\mathrm{B}}(\mathrm{p}), \mathrm{StT}_{42}{ }^{\mathrm{B}}(\mathrm{c})$ \\
\hline
\end{tabular}


Table 3: Available risk treatment strategies

\begin{tabular}{|l|l|l|l|}
\hline \multirow{2}{*}{ Strategies } & \multirow{2}{*}{$\begin{array}{c}\text { Reduced } \\
\text { probability (if } \\
\text { preventive) }\end{array}$} & $\begin{array}{l}\text { Treatment } \\
\text { action }\end{array}$ & $\begin{array}{c}\text { Reduced } \\
\text { impact }\end{array}$ \\
\cline { 3 - 4 } & & $0.5 / 0.5$ & $\begin{array}{l}\text { TU/Mu } \\
0.5\end{array}$ \\
\hline $\mathrm{StT}_{11}{ }^{\mathrm{A}}$ & & $2 / 1$ & $\mathrm{TU}$ \\
\hline $\mathrm{StT}_{11}{ }^{\mathrm{B}}$ & 0.1 & $0.5 / 0.5$ & $\begin{array}{l}\mathrm{T} 5+0.5 \\
0.5\end{array}$ \\
\hline $\mathrm{StT}_{12}{ }^{\mathrm{B}}$ & & $0 / 2$ & $\mathrm{NC}$ \\
\hline $\mathrm{StT}_{21}{ }^{\mathrm{A}}$ & 0.01 & $1 / 1$ & $0 / 2$ \\
\hline $\mathrm{StT}_{22}{ }^{\mathrm{A}}$ & & $0 / 2$ & $\mathrm{NC}$ \\
\hline $\mathrm{StT}_{21}{ }^{\mathrm{B}}$ & 0.05 & $1 / 1$ & $0 / 2$ \\
\hline $\mathrm{StT}_{22}{ }^{\mathrm{B}}$ & & $0 / 3$ & $\mathrm{NC}$ \\
\hline $\mathrm{StT}_{31}{ }^{\mathrm{A}}$ & 0.01 & $0 / 4$ & $\mathrm{NC}$ \\
\hline $\mathrm{StT}_{41}{ }^{\mathrm{A}}$ & 0.1 & $1 / 2$ & $\mathrm{T7}+1 / 1$ \\
\hline $\mathrm{StT}_{42}{ }^{\mathrm{A}}$ & & $0 / 4$ & $\mathrm{NC}$ \\
\hline $\mathrm{StT}_{41}{ }^{\mathrm{B}}$ & 0.05 & $1 / 2$ & $\mathrm{T7}+1 / 1$ \\
\hline $\mathrm{StT}_{42}{ }^{\mathrm{B}}$ & & & \\
\hline
\end{tabular}

Table 4: The results of our approach

\begin{tabular}{|c|c|c|c|c|c|}
\hline Solution & Preventive strategies & $\mathrm{Nbr} \mathrm{ScP}$ & $\%$ Pertinents & $\begin{array}{l}\text { Criticality } \\
\max \end{array}$ & $\%$ Contract respected \\
\hline \multirow[t]{4}{*}{ A } & $\varnothing$ & 18 & 66,6667 & 0,4609 & 66,6667 \\
\hline & $\mathrm{StT}_{21}{ }^{\mathrm{A}}$ & 24 & 66,6667 & 0,5205 & 45,8333 \\
\hline & $\mathrm{StT}_{41}{ }^{\mathrm{A}}$ & 18 & 50,0000 & 0,6063 & 38,8889 \\
\hline & $\mathrm{StT}_{21}{ }^{\mathrm{A}}+\mathrm{StT}_{41}{ }^{\mathrm{A}}$ & 24 & 50,0000 & 0,6801 & 12,5000 \\
\hline \multirow[t]{16}{*}{ B } & $\varnothing$ & 36 & 61,7021 & 0,2045 & 41,6667 \\
\hline & $\mathrm{StT}_{11}{ }^{\mathrm{B}}$ & 24 & 66,6667 & 0,2184 & 37,5000 \\
\hline & $\mathrm{StT}_{21}^{\mathrm{B}}$ & 48 & 66,6667 & 0,2980 & 43,7500 \\
\hline & $\mathrm{StT}_{11}{ }^{\mathrm{B}}+\mathrm{StT}_{21}{ }^{\mathrm{B}}$ & 32 & 66,6667 & 0,3193 & 37,5000 \\
\hline & $\mathrm{StT}_{41}^{\mathrm{B}}$ & 36 & 50,0000 & 0,3243 & 27,7778 \\
\hline & $\mathrm{StT}_{11}^{\mathrm{B}}+\mathrm{StT}_{41}^{\mathrm{B}}$ & 24 & 50,0000 & 0,3477 & 29,1667 \\
\hline & $\mathrm{StT}_{21}{ }^{\mathrm{B}}+\mathrm{StT}_{41}{ }^{\mathrm{B}}$ & 48 & 50,0000 & 0,4699 & 27,0833 \\
\hline & $\mathrm{StT}_{11}{ }^{\mathrm{B}}+\mathrm{StT}_{21}{ }^{\mathrm{B}}+\mathrm{StT}_{41}{ }^{\mathrm{B}}$ & 32 & 50,0000 & 0,5054 & 15,6250 \\
\hline & $\mathrm{StT}_{31}^{\mathrm{B}}$ & 36 & 66,6667 & 0,2617 & 61,1111 \\
\hline & $\mathrm{StT}_{11}{ }^{\mathrm{B}}+\mathrm{StT}_{3}{ }^{\mathrm{B}}$ & 24 & 66,6667 & 0,2799 & 50,0000 \\
\hline & $\mathrm{StT}_{21}{ }^{\mathrm{B}}+\mathrm{StT} 3_{1}{ }^{\mathrm{B}}$ & 48 & 66,6667 & 0,3804 & 45,8333 \\
\hline & $\mathrm{StT}_{11}{ }^{\mathrm{B}}+\mathrm{StT}_{21}{ }^{\mathrm{B}}+\mathrm{StT}_{31}{ }^{\mathrm{B}}$ & 32 & 66,6667 & 0,4083 & 37,5000 \\
\hline & $\mathrm{StT}_{31}{ }^{\mathrm{B}}+\mathrm{StT}_{41}{ }^{\mathrm{B}}$ & 36 & 50,0000 & 0,4138 & 33,3333 \\
\hline & $\mathrm{StT}_{11}{ }^{\mathrm{B}}+\mathrm{StT}_{31}{ }^{\mathrm{B}}+\mathrm{StT}_{41}{ }^{\mathrm{B}}$ & 24 & 50,0000 & 0,4444 & 25,0000 \\
\hline & $\mathrm{StT}_{21}{ }^{\mathrm{B}}+\mathrm{StT}_{31}{ }^{\mathrm{B}}+\mathrm{StT}_{41}{ }^{\mathrm{B}}$ & 48 & 50,0000 & 0,5985 & 12,5000 \\
\hline & $\mathrm{StT}_{11}{ }^{\mathrm{B}}+\mathrm{StT}_{21}^{\mathrm{B}}+\mathrm{StT}_{31}^{\mathrm{B}}+\mathrm{StT}_{41}{ }^{\mathrm{B}}$ & 32 & 50,0000 & 0,6446 & 6,2500 \\
\hline
\end{tabular}

